\title{
Investigation of patients with apparently inoperable lung cancer
}

\author{
RIYAD KARMY-JONES MD, ERIC VALLIERES MD, JOSEPH W LEWIS JR MD, GEORGE DUNDAS MD \\ Divisions of Thoracic Surgery, Henry Ford Hospital, Detroit, Michigan, USA; \\ Thoracic Surgery, University of Ottawa, Ottawa, Ontario; \\ and Radiation Oncology, University of Alberta, Edmonton, Alberta
}

R Karmy-Jones, E VALlieres, JW LeWis JR, G DUNDAS. Investigation of patients with apparently inoperable lung cancer. Can Respir J 1996;3(5):309-313.

Over a three-year period, 30 patients were referred to a multidisciplinary lung cancer group for palliative radiotherapy of presumed unresectable bronchogenic cancer on the basis of radiological findings. Further investigation, including surgical staging, demonstrated that 10 were candidates for surgical resection. Nine patients are alive and free of disease at a median follow-up of 25.8 months. These results demonstrate that chest $\mathrm{x}$-ray and computed tomography of the chest may not be specific enough to rule out the possibility of surgical cure.

Key Words: Lung cancer, Staging

\section{Investigation des patients atteints d'un cancer du poumon apparemment inopérable}

RÉSUMÉ : Pendant une période de trois ans, 30 patients ont été adressés à un groupe multidisciplinaire spécialisé en cancer du poumon afin de subir une radiothérapie palliative pour un cancer bronchique présumé non résécable d'après les résultats radiographiques. Une investigation plus poussée, y compris une classification par stades chirurgicaux, a démontré que 10 patients pouvaient subir une résection. Neuf patients sont vivants et en rémission après un suivi médian de 25,8 mois. Ces résultats démontrent que la radiographie et la tomodensitométrie thoracique pourraient manquer de spécificité pour rejeter la possibilité d'un traitement chirurgical.
$\mathrm{O}$ f patients presenting with bronchogenic carcinoma, roughly one-third have stage I to II disease that appears possibly amenable to surgical cure, one-third have distant metastases, and one-third have locally advanced disease that is potentially resectable (1). Of the latter, as few as $15 \%$ are candidates for surgical cure. Clinical and radiological staging (including history, physical examination, chest radiography and computed tomography $[\mathrm{CT}]$ scan) are not specific enough to rule out the possibility of resection for cure, especially when the criteria for inoperability include presumed positive mediastinal (N2 or N3) nodes (Tables 1,2) (2). We present our experience with 30 patients with bronchogenic cancer whose initial work-up suggested advanced local or regional disease. Ten patients, who were ultimately found to be candidates for surgical resection, formed the basis of this study.

\section{OBJECTIVE}

The primary objective of this report is to demonstrate that 
TABLE 1

TNM (tumour, node, metastasis) classification for staging lung cancer

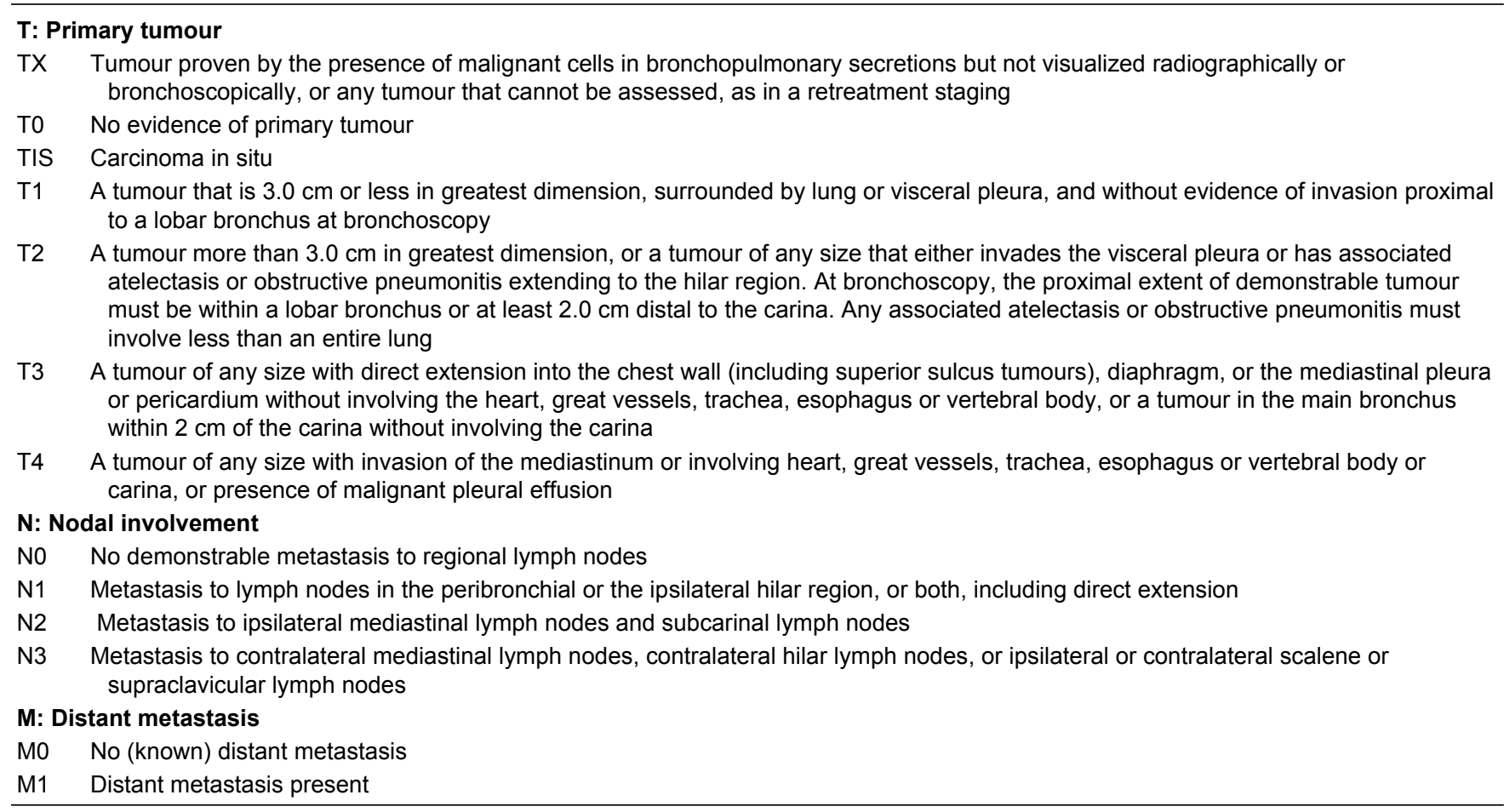

TABLE 2

TNM (tumour, node, metastasis) grouping into stages

\begin{tabular}{lccc}
\hline Stage & Tumour & Node & Metastasis \\
\hline Occult carcinoma & TX & N0 & M0 \\
Stage 0 & TIS & N0 & M0 \\
Stage 1 & T1 & N0 & M0 \\
Stage 2 & T2 & N0 & M0 \\
& T1 & N1 & M0 \\
Stage IIla & T2 & N1 & M0 \\
& T3 & N0 & M0 \\
Stage IIIb & T3 & N1 & M0 \\
& T1-3 & N1-3 & M0 \\
Stage 4 & Any T & N3 & M0 \\
\hline
\end{tabular}

patients with primary nonsmall cell cancer (NSCC) of the lung should not be ruled out for curative resection simply on the basis of CT scan. The role of surgical staging in such cases is reviewed in light of these findings.

\section{POPULATION STUDIED}

The patients who are described here were seen over a three-year period by three of the authors at the Lung Cancer Clinic at the WW Cross, a multidisciplinary group associated with the University of Alberta. The group assesses 500 to 600 cases each year. Approximately $20 \%$ of patients are referred following surgery, $20 \%$ following positive mediastinoscopy and the majority of the remainder have documented metasta- ses, physiological status precluding surgery or documented local extension beyond the limit of surgery. Very few patients (fewer than 5\%) are referred for palliative radiation on the basis of presumed, but not proven, locally advanced disease. This select subgroup is considered for aggressive staging on an individual basis to define the possibility of curative resection or entry into clinical trials.

\section{INTERVENTIONS}

Patients who appear to have the potential for surgical cure are first evaluated to determine their ability to undergo complete resection. Physiological assessment includes stair climbing, pulmonary function tests and, where needed, quantitative split lung functions. CT of the chest and upper abdomen is obtained if not already done. With elevation of serum alkaline phosphatase concentration or clinical evidence suggestive of bony metastases, bone scans are performed. Head CTs are performed based on symptomatology. If no evidence of metastatic disease is found, and the patient is deemed able to undergo resection, mediastinoscopy is performed. Four stations are routinely sampled. If mediastinoscopy is positive, the patient is given the option of enrolling in clinical trials of induction therapy. Thoracoscopy is performed in the presence of cytologically negative pleural effusion, and is considered if there is suggestion of mediastinal or vertebral invasion. If thoracoscopy is negative, the patient undergoes thoracotomy with the goal of complete resection, as defined by Mountain (3). The final stage is classified according to the TNM (tumour, node, metastasis) method described by Mountain (4) in 1986 (Tables 1 and 2) (5,6). 
TABLE 3

Preoperative characteristics of 10 patients with biopsy-proven squamous cell cancer found to be potentially resectable

\begin{tabular}{|c|c|c|}
\hline & Range & Mean \\
\hline Age (years) & $52-80$ & 67.6 \\
\hline $\mathrm{FEV}_{1}(\mathrm{~L})$ & $1.51-2.76$ & 1.75 \\
\hline$\%$ of predicted $\mathrm{FEV}_{1}$ & $65-86$ & 69.2 \\
\hline $\mathrm{FVC}(\mathrm{L})$ & $2.05-5.17$ & 2.82 \\
\hline$\%$ of predicted FVC & $74-118$ & 84.4 \\
\hline $\begin{array}{l}\% \text { of Predicted } \\
\text { DLCO }\end{array}$ & $33-90$ & 61.3 \\
\hline $\mathrm{PO}_{2}$ (torr) & $51-78$ & 66.4 \\
\hline $\mathrm{PCO}_{2}$ (torr) & $31.5-44.5$ & 36.6 \\
\hline
\end{tabular}

DLCO Carbon monoxide diffusing capacity of the lung; FEV 1 Forced expiratory volume in $1 \mathrm{~s}$; FVC Forced vital capacity

\section{MAIN RESULTS}

Between July 1991 and June 1994 approximately 1300 patients were referred to the group with new lung cancers. Thirty patients, referred for palliative radiotherapy based on radiographic evidence of local or regional advanced disease, were further investigated and found to have negative metastatic work-up. These patients underwent surgical staging. Twenty patients had positive mediastinoscopy and were randomized to induction protocols.

Ten patients (six male, four female) (Table 3) with biopsy-proven squamous cell cancer were found to be potentially resectable. CT indications of extensive local or regional disease included evidence of enlarged N2 nodes (7), mediastinal invasion (3), effusion (1) and possible adrenal metastases (1) (Table 4). In addition four patients were thought to have cardiopulmonary reserves incompatible with surgery. Eight patients had right-sided and two had left-sided lesions. Cervical mediastinoscopy was negative in all patients. The patients with left-sided lesions (\#6, \#8; Table 4) underwent anterior mediastinotomy that revealed the presence of small mobile nodes with only microscopic involvement in one patient (\#8). A fine needle aspirate of the suspected adrenal gland lesion revealed no evidence of metastatic disease. All patients were able to undergo complete resection and all were alive at a mean follow-up of 25.8 months (Table 4). One patient (\#3) presented with an untapped effusion and marginal pulmonary function; thoracentesis and thoracoscopy did not reveal evidence of malignancy and he underwent bilobectomy. Pathology revealed poorly differentiated squamous cell carcinoma and positive posterior subcarinal adenopathy. $\mathrm{He}$ declined adjuvant therapy, and unfortunately, at 11 months' follow-up, he presented with liver metastases. The other nine patients, all of whom had well-differentiated squamous cell cancer, are disease-free at the time of writing.

\section{DISCUSSION}

We have presented a series of patients who were thought, on the basis of thoracic imaging, to be inoperable because of intrathoracic spread and were referred for radiotherapy. However, surgical staging revealed that 10 were, in fact, resectable. This series demonstrates that radiological evidence
TABLE 4

Outcome and follow-up after resection in 10 patients

\begin{tabular}{|c|c|c|c|c|}
\hline $\begin{array}{l}\text { Operation } \\
\text { (patient \#) }\end{array}$ & $\begin{array}{c}\text { Preoperative } \\
\text { stage }\end{array}$ & $\begin{array}{l}\text { Final } \\
\text { Stage }\end{array}$ & $\begin{array}{c}\text { Enlarged } \\
\text { nodes }\end{array}$ & $\begin{array}{c}\text { Follow-u } \\
p \\
\text { (months) }\end{array}$ \\
\hline $\begin{array}{l}\text { Bilobectomy } \\
(\# 1)\end{array}$ & $\begin{array}{l}\text { T4N0 } \\
\text { (IIIB) }\end{array}$ & $\begin{array}{l}\text { T2N0 } \\
\text { (I) }\end{array}$ & 0 & 30 \\
\hline $\begin{array}{l}\text { Pneumonectomy } \\
(\# 2)\end{array}$ & $\begin{array}{l}\text { T2N2 } \\
\text { (IIIA) }\end{array}$ & $\begin{array}{l}\mathrm{T} 2 \mathrm{~N} 1 \\
\text { (II) }\end{array}$ & 1 & 34 \\
\hline $\begin{array}{l}\text { Bilobectomy } \\
\text { (\#3) }\end{array}$ & $\begin{array}{l}\text { T4N2 } \\
\text { (IIIB) }\end{array}$ & $\begin{array}{l}\text { T2N2 } \\
(\text { IIIA) }\end{array}$ & 3 & 17 \\
\hline $\begin{array}{l}\text { Sleeve lobectomy } \\
(\# 4)\end{array}$ & $\begin{array}{l}\text { T3N2M1 } \\
\text { (IV) }\end{array}$ & $\begin{array}{l}\text { T3N1M0 } \\
\text { (IIIA) }\end{array}$ & 1 & 33 \\
\hline $\begin{array}{l}\text { Sleeve lobectomy } \\
(\# 5)\end{array}$ & $\begin{array}{l}\text { T2N2 } \\
(\text { IIIA) }\end{array}$ & $\begin{array}{l}\mathrm{T} 2 \mathrm{~N} 1 \\
\text { (II) }\end{array}$ & 2 & 33 \\
\hline $\begin{array}{l}\text { Pneumonectomy } \\
\text { (L) (\#6) }\end{array}$ & $\begin{array}{l}\text { T1N2 } \\
\text { (IIIA) }\end{array}$ & $\begin{array}{l}\text { T1N2 } \\
\text { (IIIA) }\end{array}$ & 2 & 32 \\
\hline $\begin{array}{l}\text { Pneumonectomy } \\
\text { (R) (\#7) }\end{array}$ & $\begin{array}{l}\text { T4N2 } \\
\text { (IIIB) }\end{array}$ & $\begin{array}{l}\mathrm{T} 2 \mathrm{~N} 0 \\
(\mathrm{I})\end{array}$ & 0 & 30 \\
\hline $\begin{array}{l}\text { Pneumonectomy } \\
\text { (L) (\#8) }\end{array}$ & $\begin{array}{l}\text { T2N2 } \\
\text { (IIIA) }\end{array}$ & $\begin{array}{l}\text { T2N2 } \\
(\text { IIIA) }\end{array}$ & 1 & 22 \\
\hline $\begin{array}{l}\text { Pneumonectomy } \\
\text { (R) (\#9) }\end{array}$ & $\begin{array}{l}\text { T4N0 } \\
\text { (IIIB) }\end{array}$ & $\begin{array}{l}\text { T3N0 } \\
\text { (IIIA) }\end{array}$ & 0 & 29 \\
\hline $\begin{array}{l}\text { Pneumonectomy } \\
\text { (R) (\#10) }\end{array}$ & $\begin{array}{l}\text { T2N2 } \\
\text { (IIIA) }\end{array}$ & $\begin{array}{c}\mathrm{T} 2 \mathrm{~N} 1 \\
\text { (II) }\end{array}$ & 1 & 18 \\
\hline
\end{tabular}

L Left; R Right

of unresectable local or regional disease may not preclude a chance of complete resection and possible cure. A proportion of such patients, who are physiologically capable of withstanding curative resection and do not have extrathoracic metastases, present with chest $\mathrm{x}$-ray or CT evidence of one or more of the following: positive N2 nodal metastases; invasion of the heart, great vessels, esophagus and/or vertebrae; and malignant pleural effusion or pleural seeding. A variety of approaches are available to confirm unresectability, and should be considered to 'rationally manage' these patients (6). The fact that all the patients who were found to be operative candidates in this study had squamous cell cancer probably reflects the greater tendancy of squamous cell cancer to spread locally rather than systemically, compared with other forms of NSCC (8). In fact, the principles described apply to all forms of NSCC.

Radiological features that imply local or regional disease precluding resection include evidence of mediastinal adenopathy, mediastinal or vertebral invasion and pleural effusion. The potential role of surgical staging in each of these settings will be discussed in turn.

Initial assessment of mediastinal lymph nodes is by chest $x$-ray and chest CT. Patients with mediastinal adenopathy noted on plain chest $\mathrm{x}$-ray have only a $9 \%$ three-year survival (8). The presence of mediastinal lymphadenopathy greater than $1 \mathrm{~cm}$ in diameter, while usually indicative of metastases, does not appear to be specific enough to rule out the potential for complete resectability, and certainly pathological confirmation is required $(2,6,7)$. This can be obtained prethoracotomy by mediastinoscopy, mediastinotomy or thoracoscopy. Mediastinoscopy is safe (less than 2\% morbidity) and reduces negative exploration rates to less than $5 \%$ 


\section{TABLE 5}

1. The patient must be physiologically capable of withstanding the planned pulmonary resection

2. The planned resection must encompass the primary tumour and all draining nodal beds

3. There are no distant metastases, eg, the disease is confined to the ipsilateral hemithorax

4. If $\mathrm{N} 2$ disease is suspected, an attempt should be made to confirm histologically the presence of N2 disease before thoracotomy and, if histology is positive, the patient should be entered into prospective randomized trials. If histology is negative, the patient should proceed with thoracotomy, pulmonary resection and mediastinal lymph node dissection

5. When there is doubt as to the presence of N2 disease, the patient should be given the benefit of staging and surgical resection. Patients with obstructive pneumonia may have evidence of enlarged hilar or mediastinal adenopathy. Mediastinoscopy should be performed in these patients. (See 3 above)

6. If N2 disease is documented after surgical resection, the patient should be entered into prospective randomized trials

7. Patients with T3N2 disease confirmed histologically (by mediastinoscopy, mediastinotomy or video-assisted thorascopic surgery) should not routinely have surgical resection because postresection survival is poor. Resection may be performed for palliation

(10). Documentation of positive N2 nodes does not uniformly preclude resection. Approximately $10 \%$ of these patients have low, ipsilateral, single-station involvement with no fixation or extracapsular extension and may benefit from thoracotomy (11). Patients with left-sided lesions who have negative cervical mediastinoscopy but microscopic, although resectable, metastases to N2 nodes in the aortopulmonary window alone may also be considered for curative resection because the five-year survival rate after complete resection in the presence of only microscopic subaortic nodal disease approaches that of survival after resection of N1 disease (12). Thus, even with documented N2 disease, some patients with NSCC may be resectable, as long as the principles laid out by Putnam (2) are followed (Table 5).

Mediastinoscopy may also be considered if there is other evidence of local disease extension, such as chest wall invasion, where documented mediastinal spread would usually preclude thoracotomy. Additionally, while it may be more cost effective to avoid mediastinoscopy when CT does not reveal enlarged (greater than $1 \mathrm{~cm}$ ) mediastinal nodes, mediastinoscopy may still be appropriate in patients whose general medical condition puts them at significantly increased risk for surgery (13), because up to $15 \%$ of lymph nodes that are 'normal' by $\mathrm{CT}$ contain metastases, and mediastinoscopy may avoid a 'nontherapeutic' thoracotomy $(6,7)$. A similar situation occurs when the primary is suspected to be small cell cancer, where mediastinoscopic confirmation would also preclude thoracotomy $(6,13)$.

Apart from mediastinal adenopathy, other CT manifestations of local or regional spread that imply 'unresectability' include the suggestion of vertebral or mediastinal invasion. In the absence of obvious invasion or encirclement there may be only indirect evidence of abutment or loss of the fat plane between the malignancy and adjoining mediastinal structures. In the presence of these indeterminant findings, resectability is possible in up to $82 \%$ of cases (14). More specifically, important features to evaluate are less than $3 \mathrm{~cm}$ of contact with mediastinal structures, less than $90^{\circ}$ of contact with the aorta and the presence of a mediastinal fat plane. Resection is possible in up to $97 \%$ of cases where any one of these is present (14). Other options that should be considered include the use of esophagoscopy, bone scans, magnetic resonance imaging and angiography. Not only does prethoracotomy thoracoscopy offer a means of confirming invasion, but it should also probably be considered mandatory in the presence of pleural effusion. The resectability rate, even in the presence of cytologically negative fluid, may be as low as $5.5 \%(6,15)$. However, ultimately final staging may require thoracotomy (6).

The bulk of the above discussion has concentrated on the role and accuracy of staging in regard to the possibility of surgical extirpation. Even when prethoracotomy surgical staging confims extensive disease precluding curative resection, accurate staging may allow entry into induction protocols $(16,17)$. Major response rates in stage III bronchogenic cancers of up to $77 \%$ have been described, with five-year survival in complete responders who undergo complete resection equalling that of mediastinoscopy-negative patients (17).

\section{CONCLUSION}

Patients with NSCC of the lung may present with suggestive radiographic evidence of inoperability due to locally advanced disease. Indeed, the majority have intra- or extrathoracic spread that does preclude curative resection. However, because the specificity of such evidence is too low to rule any patient out on that basis alone, histological confirmation is required. Moreover, accurate staging allows better 'protocolization' because some of these patients may benefit from induction trials. Using the admittedly labour-intensive approach described, 10 patients who were referred as 'inoperable' candidates for radiotherapy were able to undergo complete resection, with nine being free of disease at a mean follow-up of 25.8 months.

\section{REFERENCES}

1. Johnston MR. Selection and surgical treatment options in carcinoma of the lung. Semin Roentgenol 1990;25:112-6.

2. Putnam JB Jr. Surgery for stage N2 lung cancer. Semin Thorac Cardiovasc Surg 1993;5:249-57.

3. Mountain CF. The biological operability of stage III non-small cell lung cancer. Ann Thorac Surg 1985;40:60-4. 
4. Mountain CF. A new international staging system for lung cancer. Chest 1986;89:225s-33s

5. Shields TW. Presentation, diagnosis, and staging of bronchial carcinoma and of the asymptomatic solitary pulmonary nodule. In: Shields TW, ed. General Thoracic Surgery, 4th edn. Malvern: Williams and Wilkins, 1994:1122-54.

6. Miller JD, Gorenstein LA, Patterson GA. Staging: the key to rational management of lung cancer. Ann Thorac Surg 1992;53:170-8.

7. Kerr KM, Lamb D, Wathen CG, et al. Pathological assessment of mediastinal lymph nodes in lung cancer: Implications for non-invasive mediastinal staging. Thorax 1992;47:337-41.

8. Mathews MJ, Kanhouwa S, Pickren J, Robinette D. Frequency of residual and metastatic tumor in patients undergoing curative resection for lung cancer. Cancer Chemother Rep 1973;4(Suppl):63.

9. Martini N, Fleigher BJ, Muhammad BA, et al. Results of resection in non-oat cell carcinoma of the lung with mediastinal lymph node metastases. Ann Surg 1983;198:386-97.

10. Vallieres E, Page A, Verdant A. Ambulatory mediastinoscopy and anterior mediastinotomy. Ann Thorac Surg 1991;52:1122-6.

11. Pearson FG, Delarue NC, Ilves R, et al. Significance of positive superior mediastinal nodes identified at mediastinoscopy in patients with resectable cancer of the lung. J Thorac Cardiovasc Surg 1982;83:1-11

12. Patterson GA, Piazza D, Pearson FG, et al. Significance of metastatic disease in subaortic lymph nodes. Ann Thorac Surg 1987;43:155-9.

13. The Canadian Lung Oncology Group. Investigation for mediastinal disease in patients with apparently operable lung cancer. Ann Thorac Surg 1995;60:1382-9.

14. Glazer HS, Kaiser LR, Anderson DJ, et al. Indeterminate mediastinal invasion in bronchogenic carcinoma: CT evaluation. Radiology 1989; $173: 37-42$

15. Decker DA, Dines DE, Payne WS, et al. The significance of cytologically negative pleural effusion in bronchogenic carcinoma. Chest 1978:74:640-2.

16. Rusch VW. Neoadjuvant therapy for stage III lung cancer. Semin Thorac Cardiovasc Surg 1993;5:258-67.

17. Martini N, Kris MG, Flehinger BJ, et al. Preoperative chemotherapy for stage IIIA (N2) lung cancer: the Sloan-Kettering experience with 136 patients. Ann Thorac Surg 1993;55:1365-74 


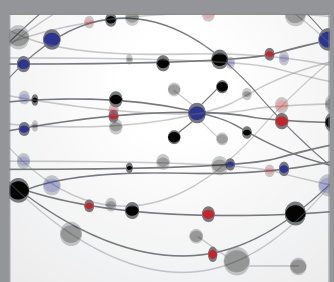

The Scientific World Journal
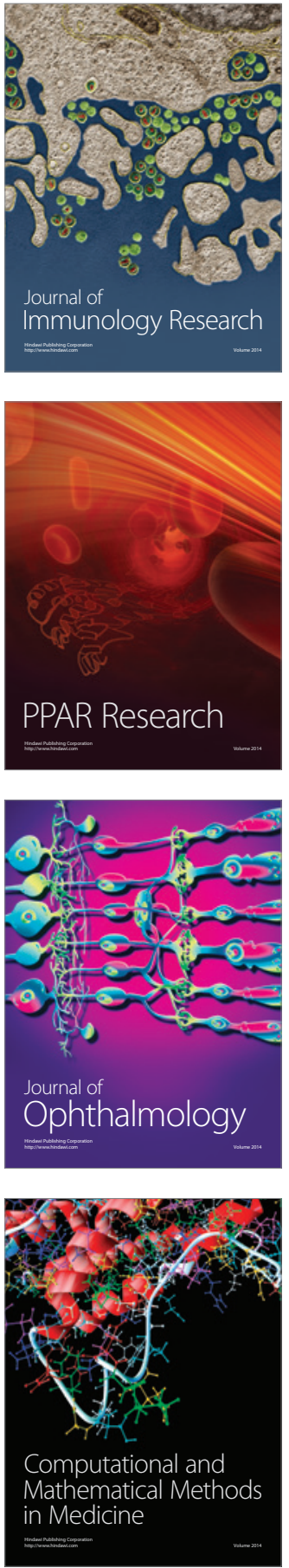

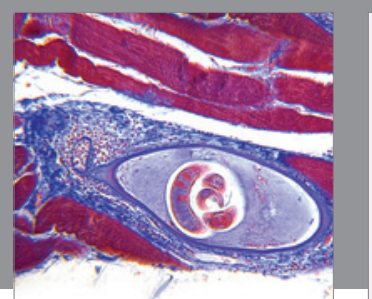

Gastroenterology Research and Practice

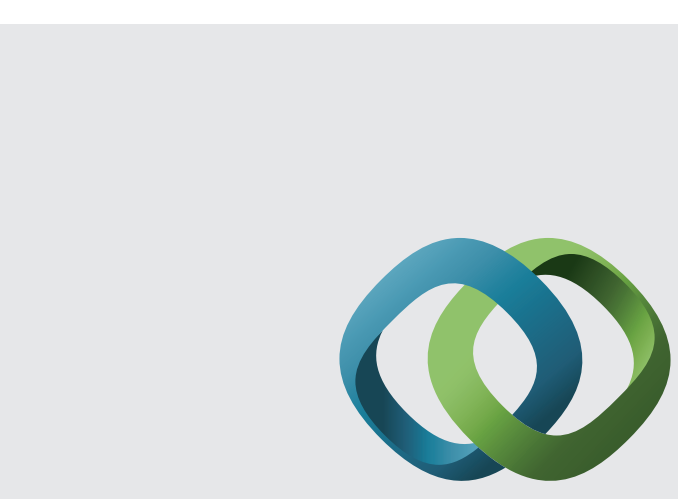

\section{Hindawi}

Submit your manuscripts at

http://www.hindawi.com
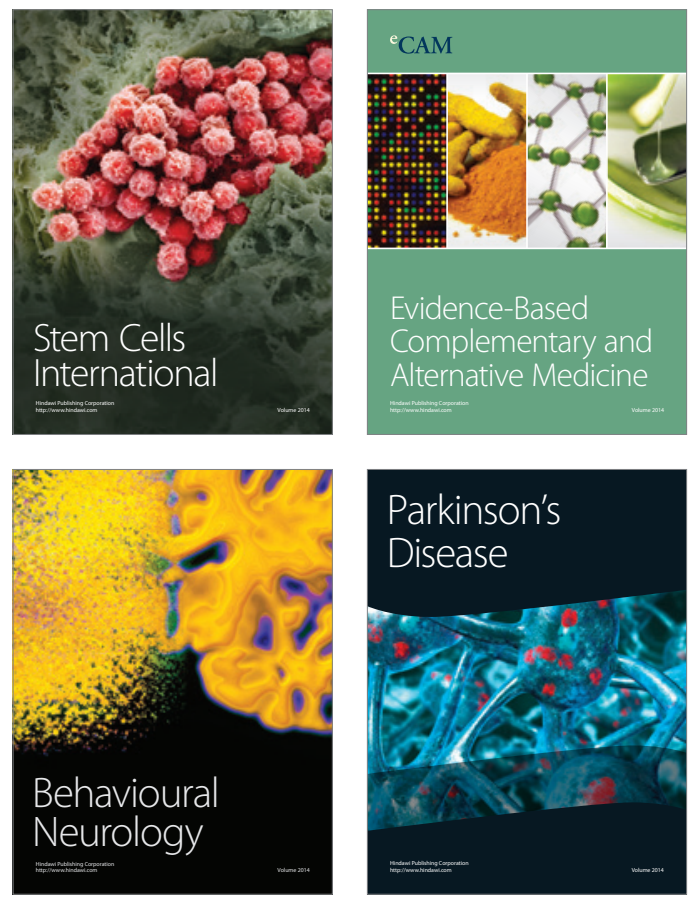
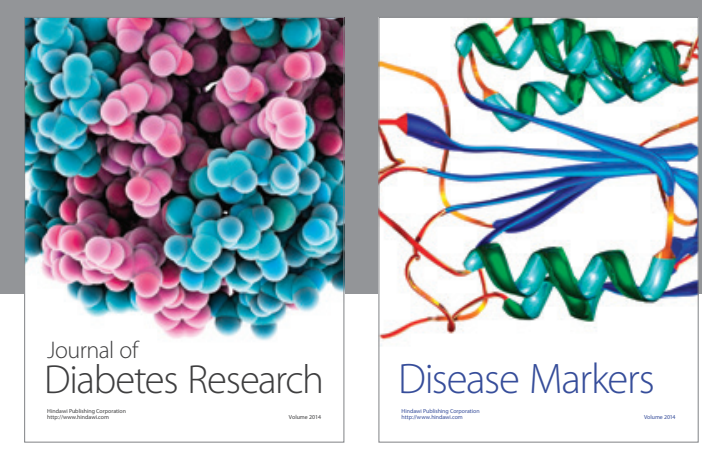

Disease Markers
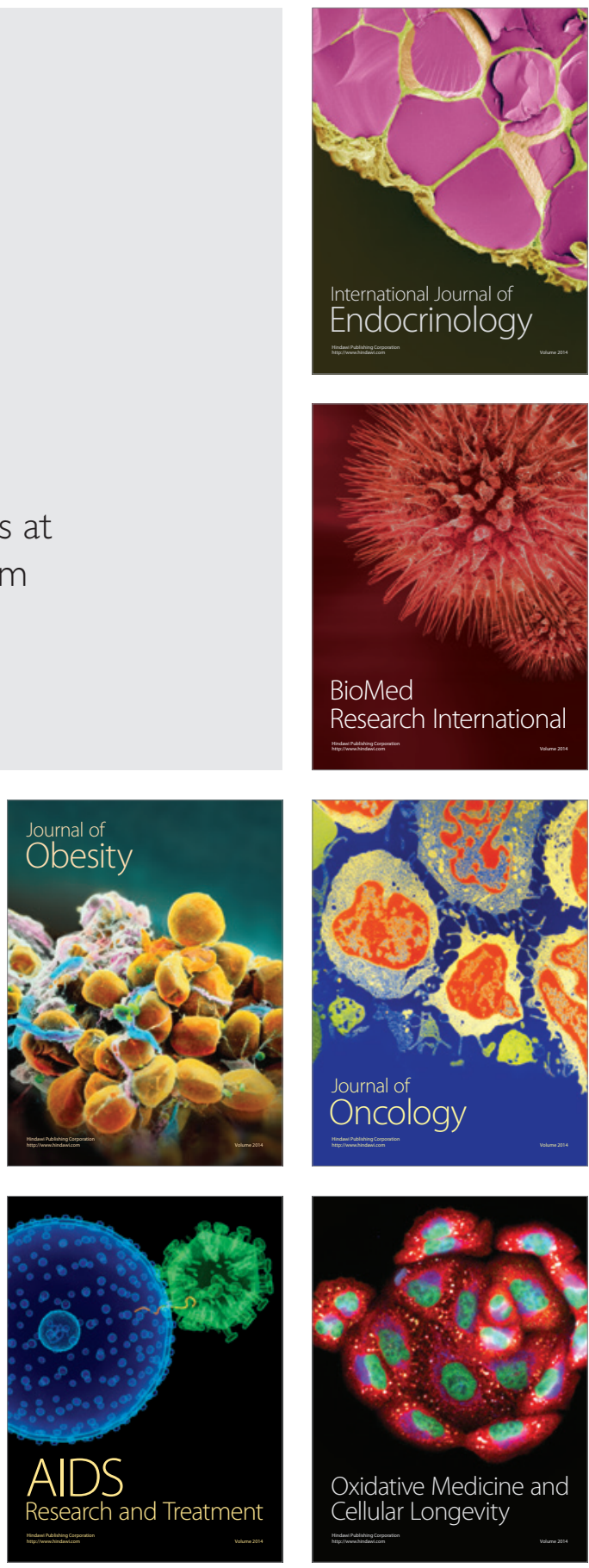